\title{
Sol-Gel Processed Indium-Doped Zinc Oxide Thin Films and Their Electrical and Optical Properties
}

\author{
Radhouane Bel-Hadj-Tahar1,2, Abdellatif Belhadj Mohamed2 \\ ${ }^{1}$ Department of Chemistry, Faculty of Science, King Khalid University, Abha, KSA \\ ${ }^{2}$ Photovoltaic Laboratory, Research and Technology Center of Energy, Borj-Cedria Science and Technology Park, \\ Hammem-Lif, Tunisia \\ Email: belhadjtahar2001@yahoo.com
}

Received 5 August 2014; revised 5 September 2014; accepted 4 October 2014

Copyright (C) 2014 by authors and Scientific Research Publishing Inc.

This work is licensed under the Creative Commons Attribution International License (CC BY). http://creativecommons.org/licenses/by/4.0/

(c) (i) Open Access

\begin{abstract}
Transparent conducting films of zinc oxide and indium-doped zinc oxide have been prepared by a simple and economical sol-gel technique. This process is feasible for the fabrication of high quality TCO thin films when the processing parameters are optimized. It was found that the out-diffusion of oxygen during the vacuum annealing step was a crucial factor to prepare thin layer with superior properties. Annealing lowers the resistivity down to $4.710^{-3} \Omega \cdot \mathrm{cm}$ for the 1 at.\% doped films due to the liberation of high-valency In-dopants and the enhanced film density. At high indium concentrations, the free electron density stabilizes because an increasing number of dopant atoms form some kinds of neutral defects. The neutralized indium atoms do not contribute free electrons. The feasibility to deposit highly transparent ZnO thin films has been demonstrated.
\end{abstract}

\section{Keywords}

Zinc Oxide, Doping, Electro-Optical Properties, Sol-Gel

\section{Introduction}

Zinc oxide thin films have been actively investigated as transparent conducting oxide (TCO) to substitute indium tin oxide (ITO) due to price volatility associated with indium, along with various supply concerns. In addition, this compound is basically composed of zinc which is an inexpensive, nontoxic, and easily available element. Moreover, zinc oxide is relatively stable in the presence of hydrogen plasma, which is of significance for applications related to amorphous silicon solar cells. Apart from these advantages it should be remarked that 
nonconducting $\mathrm{ZnO}$ coatings are also widely studied and used owing to their important applications to piezoelectric devices, electroluminescent displays, and gas sensors [1]. A vast literature has been particularly focused on the development of $n$-type zinc oxide films. Nevertheless, several attempts have been reported on $p$-type zinc oxide films for the production of ZnO-based devices. Doping with aluminum, gallium, boron, germanium, and indium has been investigated by many groups using different depositing techniques. A number of processing routes have been used which have resulted in the preparation of thin layers with a variety of properties. In particular, the values reported for the electrical resistivities are relatively divergent and have not changed significantly, despite the large number of groups working in the field of TCO materials. This suggests that a physical limitation probably exists which prevents reaching resistivities lower than $1 \times 10^{-4} \Omega \cdot \mathrm{cm}$ and mobilities larger than about $40 \mathrm{~cm}^{2} / \mathrm{V} \cdot \mathrm{s}$. This situation has directed the research toward discovering new materials having high electronic mobility. Ternary and quaternary systems based on the association of the currently used elements are among the possible potential alternatives.

Recently, $\mathrm{In}_{2} \mathrm{O}_{3}(\mathrm{ZnO})$ system has become a particular focus of attention due to its good electro-optical properties associated with excellent chemical stability. Indium-doped zinc oxide (IZO) thin films have been accomplished using different techniques, including spray pyrolysis [2]-[10], chemical vapor deposition [11], e-beam evaporation [12], pulsed laser deposition [13]-[15], and sputtering [16]-[20]. Most of these techniques require sophisticated instruments and/or high deposition temperature. In this respect, sol-gel processing offers several advantages including careful control of chemical composition, high purity, and it enables film deposition in a conventional environment without the need for expensive equipments. The suitable manipulation of precursor solutions allows for the fabrication of advanced materials in a wide variety of forms including thin film coatings and very homogeneous powders. Despite all these advantages, very few reports [21] [22] are published on solgel processed IZO thin films. Therefore, it was the aim of the present work to identify some of the factors involved in the sol-gel processing of In-doped zinc oxide and to optimize processing parameters to attain reproducible high-quality thin layers and properties. In this work, the elero-optical properties of IZO films are interpreted taking into account the intrinsic characteristics of sol-gel technique, which is very different from the other physical and chemical methods.

\section{Experimental Details}

The zinc precursor solution was prepared by dissolving zinc acetate dihydrate $\left[\mathrm{Zn}\left(\mathrm{CH}_{3} \mathrm{CO}_{2}\right)_{2} \cdot 2 \mathrm{H}_{2} \mathrm{O}\right]$ in isopropanol $\left[\left(\mathrm{CH}_{3}\right)_{2} \mathrm{CHOH}\right](99.5 \%$, Sigma-Aldrich) under continuous stirring for $10 \mathrm{~min}$. The use of metal acetate is preferred to commonly used metal alkoxide precursors which are known to be sensitive toward moisture. In addition, smooth topography has been reported [23] for $\mathrm{ZnO}$ films grown from zinc acetate. Diethanolamine was used as a complexing agent to keep the metal ions (zinc and indium) in homogeneous solution, which leaves sufficient flexibility for the system to exist homogeneously without undergoing precipitation. The amount of DEA in the starting solution has been optimized (DEA/Zn $=2$ in molar ratio) and the final solution was 0.3 $\mathrm{mol} \cdot \mathrm{l}^{-1}$. At this stage, adequate amount of indium was added from an indium precursor solution to prepare IZO thin films. The indium solution is composed of indium acetate-diethanolamine mixture (molar ratio of DEA/In = 2 ) in isopropanol. The detailed preparation of this solution is published elsewhere [24]. This system is relatively simple as it avoids the refluxing and distillation procedures figuring in most of the schemes reported for sol-gel processed films. The optimum amount of DEA in the system provided a homogeneous distribution of the metal ions and prevented their segregation/precipitation from the solution. The deposition conditions being independently varied including dopant concentration, firing temperature as well as post-deposition treatments which were conducted at various temperatures. Process optimization was accomplished primarily by fabricating IZO thin films under various conditions, and once suitable hydrolysis and thermal processing conditions had been identified, thin layers were deposited.

Solutions were deposited onto glass plates (Corning 7059, Corning Glass Works, Corning, NY) using an optimized withdrawal speed of $5 \mathrm{~cm} / \mathrm{min}$ to give uniform layers. After deposition, the films were first dried at $100^{\circ} \mathrm{C}$ for $10 \mathrm{~min}$ to remove volatile organic species (such as residual solvent) and then pyrolized at $450^{\circ} \mathrm{C}$ for $30 \mathrm{~min}$ to promote densification and crystallization. After pyrolysis, the films were allowed to cool to room temperature. Selected samples were annealed in vacuum $\left(\sim 10^{-3}\right.$ Torr $)$ at $450^{\circ} \mathrm{C}$ for one hour to improve their electrical properties. Annealing at higher temperatures resulted in opaque films. Optimum deposition temperatures of $430^{\circ} \mathrm{C}$ [6] and $450^{\circ} \mathrm{C}$ [3] and a subsequent annealing in vacuum $\left(\sim 10^{-5} \mathrm{Torr}\right)$ at about $377^{\circ} \mathrm{C}$ [25] has 
been used for sprayed IZO thin films but there was no indication on their appearance. Other reducing environments such as $15 \% \mathrm{H}_{2} / \mathrm{N}_{2}$ or $100 \% \mathrm{~N}_{2}$, at temperatures between $300^{\circ} \mathrm{C}$ and $450^{\circ} \mathrm{C}$ have been also tried [19].

The doping level $C_{\text {In }}$ varied up to 3 at.\%. The thermal behavior of the solutions was studied using simultaneous thermogravimetric analysis (TGA) and differential thermal analysis (DTA) (Model TA-50 WS, Shimadzu, Kyoto, Japan). All thermal analyses were done at a heating rate of $5^{\circ} \mathrm{C} / \mathrm{min}$ in air atmosphere. Investigation of thin-film growth was carried out by X-ray analysis (Model 2024, Rigaku Co., Tokyo, Japan) at room temperature. An atomic force microscope (AFM, Seiko Instrument Inc. SPI 38,000 N) was used to examine the morphology of the films.

The film thickness was determined from the interference bands that were observed in the visible spectra (Model U-3500, Hitachi Co., Tokyo, Japan). The electrical properties, resistivity $(\rho)$ and Hall coefficient (Resitest 8300 , Toyo Technica) of the as deposited and annealed samples were measured at room temperature using the van der Pauw technique with indium ohmic electrodes.

\section{Results and Discussions}

\subsection{Thermo-Gravimetric and Differential Thermal Analysis}

Knowledge of the different bulk transformations that occur on sintering can assist interpretation of certain film properties. However, one should note that the TG/DTA results should not be directly extrapolated to the case of a film, because they were recorded on gel powders and at a slow heating rate, whereas the films prepared in this study were rapidly calcined in a preheated furnace [26]. The weight loss of the dried gel as a function of temperature indicates there are distinct temperature regions for decomposition. The entire thermal effect accompanied by a total weight loss of $70 \%$ in the TG curve (Figure 1). DTA curve indicates that the metal complexes decompose exothermally between $300^{\circ} \mathrm{C}$ and $500^{\circ} \mathrm{C}$. The crystallization onset temperature is about $430^{\circ} \mathrm{C}$ and the peak temperature of crystallization is $470^{\circ} \mathrm{C}$. The exothermic decomposition of the precursor mass resulted in in-situ temperatures which facilitated the formation/crystallization of $\mathrm{ZnO}$ phase at relatively lower external temperature.

\subsection{Structural Features}

Figure 2 shows a representative X-ray diffraction spectrum for zinc oxide film with well defined peaks corresponding to the hexagonal crystalline structure. The film is randomly oriented. The indium dopant does not have significant influence on the X-ray diffraction patterns. The doped films give the same diffraction patterns as the undoped samples. We have previously shown [27] that the crystallite orientation can simply and intentionally be tailored by choosing an adequate solvent-chelating ligand combination. We also demonstrated that the film electronic conductivity is independent of the degree of c-axis orientation. Therefore, in the present work we did not use methoxyethanol-monoethanolamine system which yields highly oriented films to avoid the toxicity of methoxyethanol solvent.

Three-dimentional AFM pictures of three $\mathrm{ZnO}$ samples and their two-dimentional projections are given in Figure 3 . The crystallites are slightly elongated, with a tendency for the In-doped material to show larger grains.
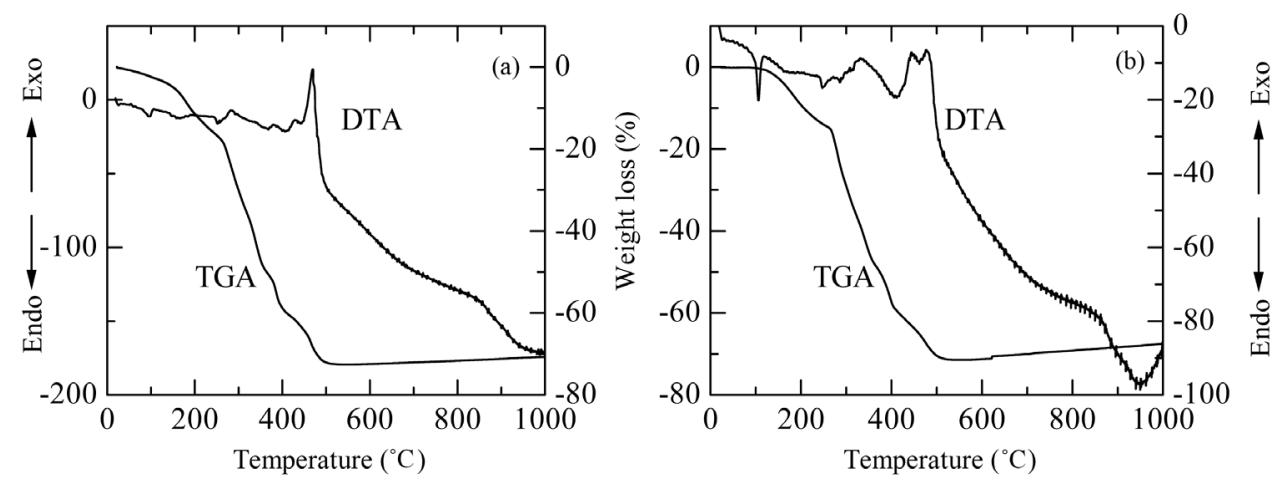

Figure 1. TGA/DTA curves recorded at a heating rate of $5^{\circ} \mathrm{C} / \mathrm{min}$ for (a) 2 at.\% In-doped and (b) pure $\mathrm{ZnO}$ gel powders. 


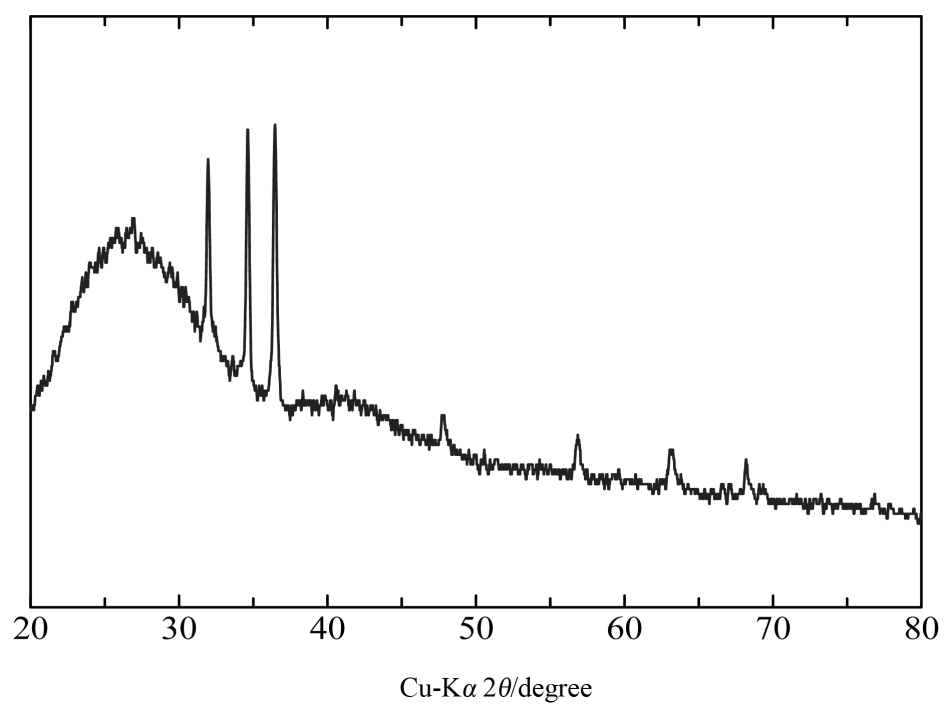

Figure 2. X-ray diffractogram for $\mathrm{ZnO}$ thin film that was fired at $650^{\circ} \mathrm{C}$ for $30 \mathrm{~min}$.
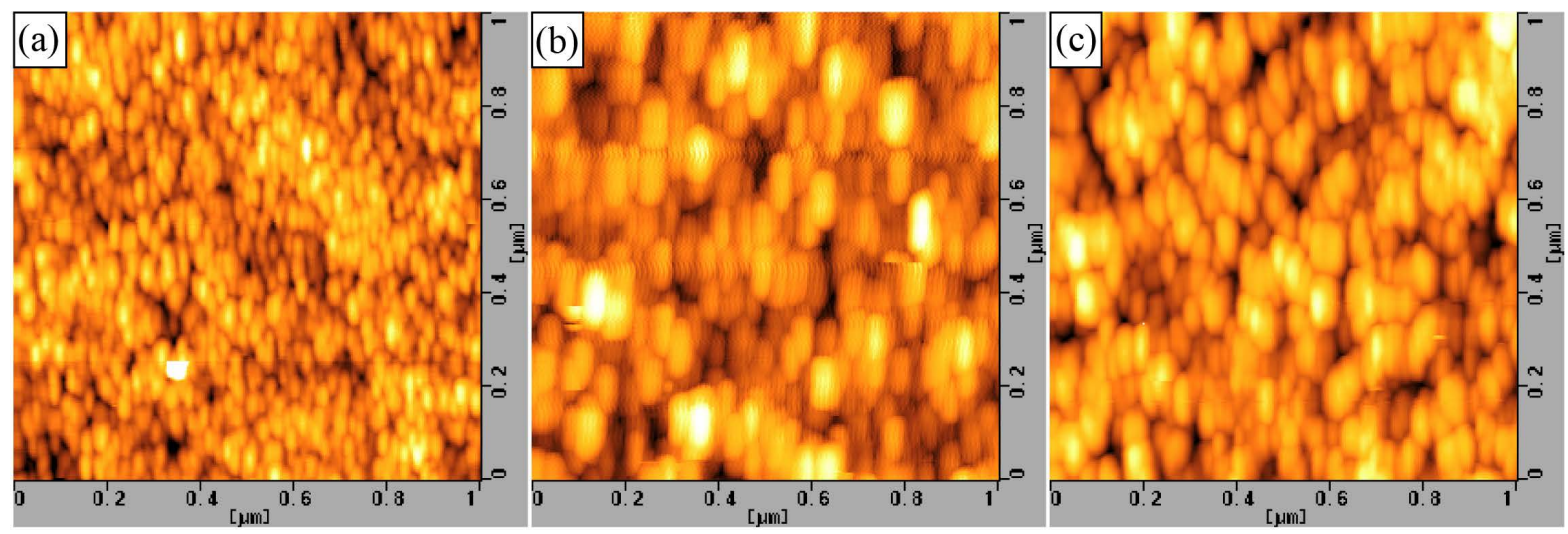

Figure 3. AFM images for (a) pure zinc oxide; (b) 0.8 at.\% In; and (c) 3 at.\% In-doped zinc oxide.

The presence of intergranular voids partly explains the relatively low film densities. The increase in grain size for the doped specimens may be ascribed to the lesser number of nucleation sites in the amorphous oxide layer. This result is in contrast to what is generally observed for tin-doped indium oxide where the grain growth is inhibited by the addition of the dopant.

\subsection{Electrical Properties}

The measured changes in electrical resistivity $(\rho)$, carrier concentration $(n)$, and Hall mobility $(\mu)$ for the as-deposited and vacuum annealed IZO thin films are presented in Table 1 . The resistivity decreases sharply with increasing In content up to 1 at.\% and then increases with further addition of In. The lowest resistivity is $\rho_{\min }=4.7 \times 10^{-3} \Omega \cdot \mathrm{cm}$, obtainable only under reduced condition. The corresponding carrier concentration and Hall mobility are $1.2 \times 10^{20} \mathrm{~cm}^{-3}$ and $11 \mathrm{~cm}^{2} / \mathrm{V} \cdot \mathrm{s}$, respectively. Very low mobility values are obtained for the as-deposited films regardless of the doping concentration. Vacuum annealing results in a remarkable increase in both the electronic mobility and the electron concentration which remains far below that calculated assuming that every dissolved indium atom supplies one free electron. In fact, with increasing doping concentration, less than $40 \%$ of In incorporated contributes one excess electron to the conduction band. The same trend is observed for the mobility values which are smaller than that of single $\mathrm{ZnO}$ crystals $\left(180 \mathrm{~cm}^{2} / \mathrm{V} \cdot \mathrm{s}\right)$ [28]. Essentially, the same behavior was observed for zinc oxide films doped with aluminum [26] [27] or boron [29]. Scattering at grain boundaries is sometimes postulated in polycrystalline films with small crystallite size. This mechanism 
Table 1. Electrical properties and doping efficiency for the as deposited and vacuum annealed IZO films.

\begin{tabular}{|c|c|c|c|c|c|c|c|c|c|c|}
\hline \multirow[b]{2}{*}{ at.\% In } & \multicolumn{2}{|c|}{$\begin{array}{l}\text { Hall mobility }(\mu) \\
\left(\mathrm{cm}^{2} / \mathrm{V} \cdot \mathrm{s}\right)\end{array}$} & \multicolumn{2}{|c|}{$\begin{array}{l}\text { Carrier concentration } \\
\qquad\left(1019 \mathrm{~cm}^{-3}\right)\end{array}$} & \multicolumn{2}{|c|}{$\begin{array}{l}\text { Resistivity }(\rho) \\
\left(10^{-3} \Omega \cdot \mathrm{cm}\right)\end{array}$} & \multicolumn{2}{|c|}{$\begin{array}{l}\text { Sheet resistance } \\
\qquad\left(\times 10^{4} \Omega / \square\right)\end{array}$} & \multicolumn{2}{|c|}{ Doping efficiency ${ }^{\mathrm{a}}(\%)$} \\
\hline & As-deposited & Annealed & As-deposited & Annealed & As-deposited & Annealed & As-deposited & Annealed & As-deposited & Annealed \\
\hline 0 & 0.6 & 5.2 & 0.5 & 0.8 & 2100 & 149 & 6.69 & 0.74 & $\ldots$. & $\ldots$ \\
\hline 0.6 & 1.1 & 10.5 & 0.3 & 9.6 & 1806 & 6.2 & 6.79 & 0.03 & 1.2 & 38.1 \\
\hline 0.8 & 1.3 & 11.3 & 0.3 & 8.5 & 8.5 & 6.5 & 6.30 & 0.03 & 0.9 & 25.3 \\
\hline 1 & 0.1 & 11.0 & 4.1 & 12.0 & 12.0 & 4.7 & 6.45 & 0.02 & 9.8 & 28.6 \\
\hline 1.4 & 0.1 & 9.3 & 2.3 & 10.7 & 10.7 & 6.3 & 7.16 & 0.03 & 3.9 & 18.2 \\
\hline 2 & 0.1 & 7.6 & 2.9 & 11.2 & 11.2 & 7.4 & 5.82 & 0.03 & 3.45 & 13.3 \\
\hline 3 & 0.1 & 6.9 & 3.0 & 17.0 & 17.0 & 5.3 & 5.97 & 0.03 & 2.4 & 13.5 \\
\hline
\end{tabular}

${ }^{\mathrm{a}}$ Ratio of measured carrier concentration to that calculated under the assumption that every dissolved In atom supplies one free electron: $n \times 100 / 4.2 \times$ $10^{20} C_{\text {In }}$.

seems to be less important in our samples since the free path length of electrons was much smaller than the crystallite size. Excess indium above certain critical concentration seems to form neutral defects rather than generating carriers. Therefore, the source of the problem is likely to be connected with the appearance of additional phases. Lee et al. [2] have studied $\mathrm{In}_{2} \mathrm{O}_{3}-\mathrm{ZnO}$ system in the form of thin films. They have observed the presence of $\operatorname{In}_{2} \mathrm{O}_{3}$ and $\mathrm{Zn}_{k} \mathrm{In}_{2} \mathrm{O}_{k+3}(k=2-5)$ phases. They attributed the modest Hall mobility values measured for their films to the scattering by these structures. Goyal et al. [30] have studied IZO sprayed films using X-ray photoelectron spectroscopy. They suggested that indium atoms are probably forming an unknown complex. A quantitative analysis [31] of the electronic mobility has shown that the scattering at neutral and ionized defects prevails in the intermediate temperature range as acoustic and optical phonons are not excited. Jin et al. [32] have found that the free electron is predominantly scattered by ionized impurities in $\mathrm{ZnO}$ :Al films made by reactive sputtering. On the basis of anion interstitial model, Frank and Köstlin [33] have successfully demonstrated the formation of the following neutral defects for the sprayed ITO films: ionizable $\left(\mathrm{Sn}_{2} \mathrm{O}_{\mathrm{i}}{ }^{\prime \prime}\right)$ complex, non ionizable $\left(\mathrm{Sn}_{2} \mathrm{O}_{4}\right)^{x}$ complex and an $\left(\mathrm{Sn}_{2} \mathrm{O}_{\mathrm{i}}{ }^{\prime \prime}\right)\left(\mathrm{Sn}_{2} \mathrm{O}_{4}\right)^{x}$ associate.

The amount of oxygen present while depositing the films by physical methods can be easily controlled by adjusting the oxygen mass-flow rate which is not the case for chemically prepared layers. Therefore, for the latter techniques, the post treatment is rather essential as in the present case. Oxygen rich atmosphere may damage the films by introducing defects because $\mathrm{In}^{3+}$ ion pair may attract an additional oxygen atom which plays the role of electron trap. The oxygen content is expected to increase with increasing $C_{\mathrm{In}}$, which is consistent with In substituting $\mathrm{Zn}$. Thus, the success of the subsequent vacuum annealing step in reactivating the [In] derived carriers will depend on how tightly oxygen is bonded to the dopant. Ku et al. [34] have shown that oxygen content in sputter gas is a critical parameter that decides the electrical properties of the IZO films prepared by radio frequency magnetron sputtering. Many groups [7] [20] [35] [36] reported that the resistivity of IZO films increases as a function of heat treatment time and temperature in oxygen atmosphere. Another important cause for the relatively low carrier densities is the porous nature of the sol-gel processed layers (low refractive indices, Table 2) which facilitates oxygen indiffusion [37]. Although denser films are obtained after post-deposition treatment, their refractive indices remain below that reported for zinc oxide single crystal (2.02) [38] [39]. The reduction in film thickness by annealing is a result of film densification (relatively higher refractive indices).

In view of the preceding discussion, it is clear that the enhanced electrical conductivity after vacuum annealing is due to the cumulative effect of film densification and decrease in the concentration of neutral defects. Since scattering at ionized defects cannot be avoided (high values of $n$ are required), research in the field of transparent conductors should be directed towards exploring new materials with high electronic mobility. Binary, ternary and quaternary oxides based on the association of those currently in use represent a possible alternative. In the last few years, many groups [40] [41] have been studying various oxide combinations.

\subsection{Optical Properties}

Figure 4 shows the transmittance of a representative $\mathrm{ZnO}$ film doped 0.8 at.\% In before and after annealing. The as deposited films has a transmittance in the visible higher than $90 \%$ which slightly decreases following 
Table 2. Dependence of the thicknesses and the refractive indices of the $\mathrm{ZnO}$ films on indium concentration and vacuum annealing treatment.

\begin{tabular}{ccccc}
\hline \multirow{2}{*}{$\begin{array}{c}\text { Doping level } \\
\text { (at.\% In) }\end{array}$} & \multicolumn{2}{c}{ Film thickness $(\mathrm{nm})$} & \multicolumn{2}{c}{ Refractive index } \\
\cline { 2 - 5 } 0.0 & As-deposited & Annealed & As-deposited & Annealed \\
0.6 & 284 & 272 & 1.82 & 1.86 \\
0.8 & 223 & 204 & 1.76 & 1.90 \\
1 & 256 & 231 & 1.79 & 1.86 \\
1.4 & 239 & 197 & 1.80 & 1.96 \\
2 & 268 & 227 & 1.72 & 1.85 \\
3 & 289 & 273 & 1.67 & 1.75 \\
\hline
\end{tabular}

annealing. Here, it is worth to note that the transmission spectra were recorded on both-side coated samples using air as reference. The high transmittance in the luminous range makes $\mathrm{ZnO}$ :In of interest as a window coating. The wavelength at which full absorbance is observed for the annealed films has shifted to a shorter- $\lambda$ region, partly because of the Moss-Burstein effect. The degree of the blue shift depended on both indium content and vacuum annealing. A recent report [22] on spin-coated (IZO) films has shown that the values of direct band gap decreased with increase in the In content.

The optical band gap of $\mathrm{ZnO}$ can be estimated from the absorption data. At the absorption edge, the film transmittance is $T \approx \exp (-\alpha t)$, where $t$ is the film thickness [42]. For direct band-to-band transition, the energy dependence of the absorption coefficient can be described by the relation for parabolic bands [43] $\alpha=A(h v-E g)^{x}$, where $h v$ is the photon energy and $E g$ is the energy band gap. The value of $x=1 / 2$ for allowed direct transition and 3/2 for forbidden direct transition. Figure 5 shows the photon energy dependence of $\alpha^{2}$ for the as-deposited and the annealed 1 at.\% In-doped film. The straight line in this figure was extrapolated to $\alpha=0$, and the energy axis intercept was taken as the band value. This figure clearly shows a positive shift, which can be expected from the substantial increase in the free carrier concentration as a result of the annealing. Band gap widening has been reported for nonstoichiometric $\mathrm{ZnO}$ (Refs. [44] and [45]) and IZO thin films [46] [47].

The band gap widening is usually interpreted in terms of Burstein-Moss (BM) shift [48] resulting from the filling up of lower levels in the conduction band. Assuming parabolic bands, this shift can be described for doped material as:

$$
\Delta E_{g}^{\mathrm{BM}}=\frac{\hbar^{2}}{2 \mathrm{e} m_{v c}^{*}}\left(3 \pi^{2} n\right)^{\frac{2}{3}}(\mathrm{eV}) .
$$

With the reduced effective mass

$$
\frac{1}{m_{v c}^{*}}=\frac{1}{m_{v}^{*}}+\frac{1}{m_{c}^{*}} .
$$

The (BM) model predicts an energy-gap shift proportional to $n_{e}^{2 / 3}$.

However, the (BM) band-filling effect that shifts positively the band-edge energy might be partly counteracted by band gap shrinkage due to electron-electron and electron-impurity scattering. The band gap narrowing has been studied in heavily doped $\mathrm{ZnO}$ [44] [49] and ITO [50]. According to Wolff [51], in heavily n-doped semiconductors the conduction band is shifted downward by the energy.

$$
\Delta E^{e i}=-\left(\frac{\mathrm{e}}{2 \pi \varepsilon_{0} \varepsilon_{r}}\right)\left(\frac{3}{\pi}\right)^{\frac{1}{3}} n^{\frac{1}{3}}(\mathrm{eV})
$$

where $\varepsilon_{r}$ is the dielectric constant.

The band gap magnitude of polycrystalline zinc oxide $E_{g_{0}}$ depends on the detailed preparation conditions 


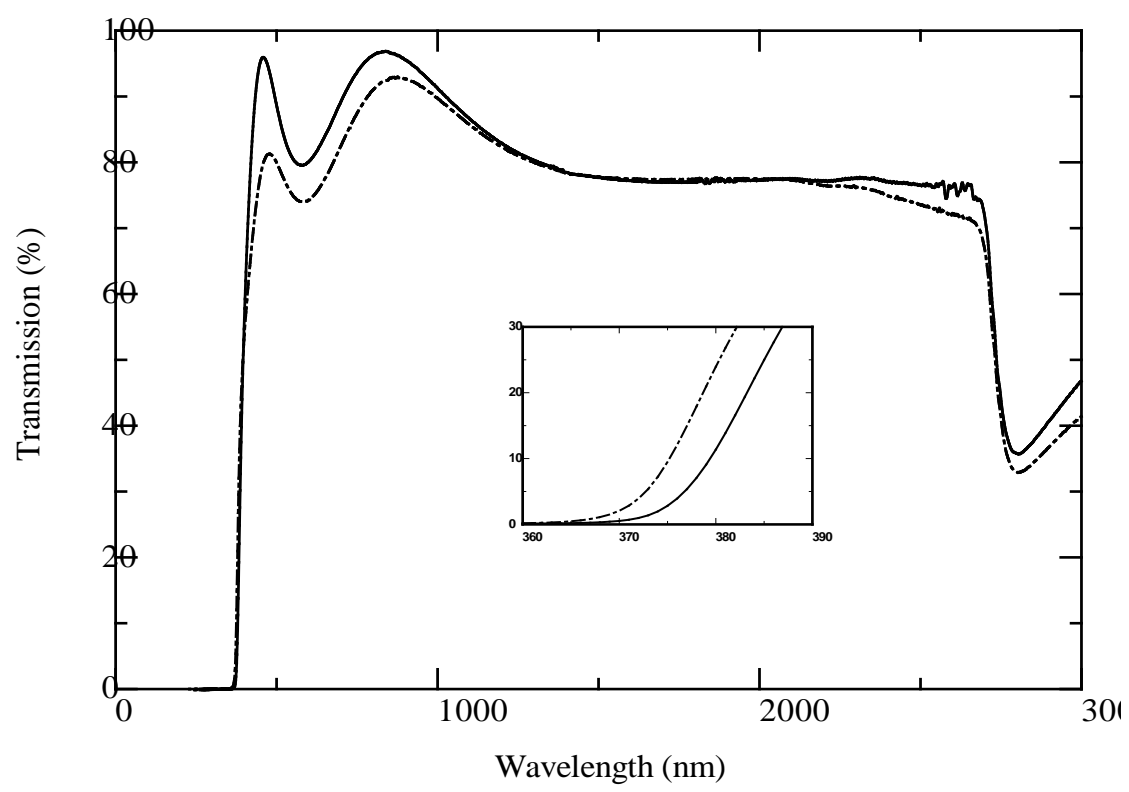

Figure 4. Visible spectra of $\mathrm{ZnO}$ thin film doped with 0.8 at.\% In before (solid line) and after vacuum annealing (dash dotted line).
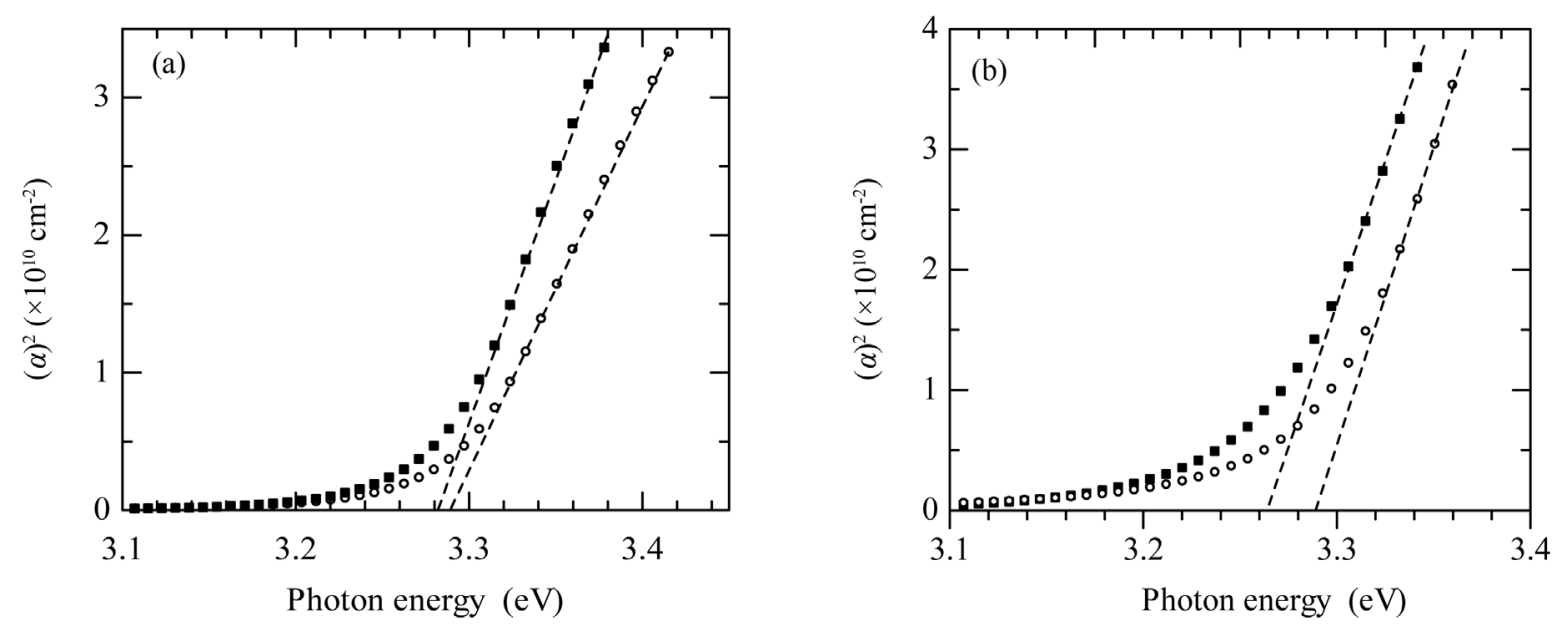

Figure 5. Plots of $(\alpha)^{2}$ against (hv) for (a) pure and (b) 1 at.\% In-doped ZnO thin films before ( $\square$ ) and after ( $\square$ ) vacuum annealing at $450^{\circ} \mathrm{C}$ for one hour.

[50]. Its value is reported to range from $3.28 \mathrm{eV}$ for insulating $\mathrm{ZnO}$ to $3.38 \mathrm{eV}$ for highly conductive films. Pure zinc oxide films prepared in this work have $E_{g_{0}}=3.28 \mathrm{eV}$. Therefore, the absorption edge shift in indium-doped ZnO layers was taken as the difference between the optical gap $\left(E_{g}\right)$ and this value $\left(E_{g_{0}}\right)$. Taking $m_{c}^{*}=0.38 m_{0}, m_{v}^{*}=1.8 m_{0}$ [52], and $\varepsilon_{r}=8.5$ [53], the absorption edge shift can then be evaluated by

$$
\Delta E=E_{g}-E_{g_{0}}=\Delta E_{g}^{\mathrm{BM}}-\Delta E^{e i} .
$$

Figure 6 shows comparison between theory and experimental data for 13 samples which were prepared at the same conditions but with different doping levels. For the samples prepared in this work, the net effect of the above competing mechanisms is to slightly increase the gap. However, the band gap shift remains below that theoretically predicted (dashed line) for all of the prepared thin films. The difference in the absorption shifts between the calculated and measured values may be attributed to other many body effects which lead to further band gap narrowing. Sernelius [49] [54] reported that in polar semiconductor, there is a displacement of charge from one type of atoms to the other. Thus, the host atoms become weakly charged. A moving, charged particle 


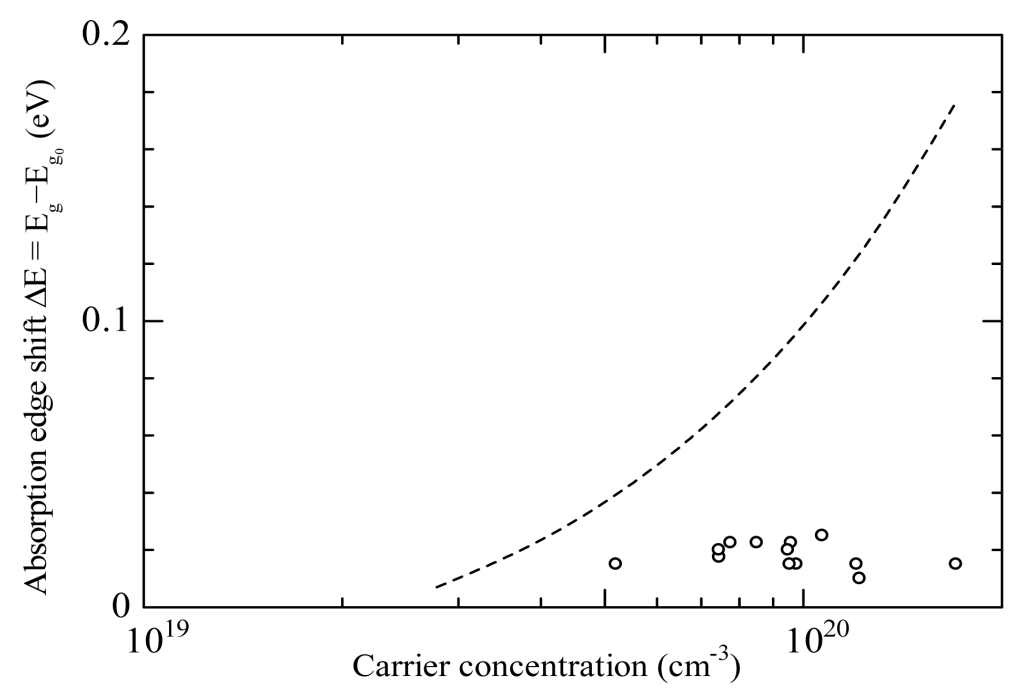

Figure 6. Absorption edge shift $\Delta E$ as a function of carrier concentration. Dashed line represents the calculated $\Delta E=\Delta E^{\mathrm{BM}}-\Delta E g^{e i}(\mathrm{eV})$.

causes a displacement polarization, which follows the particle in the crystal. An electron attracts the positively charged atoms and repels the negatively charged ones. Effectively the electron is surrounded by a charge cloud, of positive charge. Similarly, a valence and hole is surrounded by a charge cloud of negative charge. The particle and its charge cloud can be considered as a new particle, a polaron. The displacement causes negative energy contributions.

Theoretical models [55] include band gaps shifts due to the blocking of the lowest states in the conduction band, electron interaction, and impurity scattering (the $\mathrm{In}^{3+}$ ions, which replace lattice site $\mathrm{Zn}^{2+}$, behave as singly charged scatters). For the thin films that were analyzed in the present work, and since more than $60 \%$ of the dopant remains electrically inactive, a major part of indium is likely to form neutral impurities especially for non-annealed samples (see Table 1). Therefore, these impurities among other possibly ignored factors which contribute to $\Delta E$ should not be neglected.

\section{Conclusion}

We have used sol-gel process as a simple low-cost technique for the preparation of IZO thin films. It can be concluded that indium acts as an effective donor in zinc oxide up to a certain concentration and supplies a single free electron resulting from $\mathrm{In}^{3+}$ ion on a substitutional site of $\mathrm{Zn}^{2+}$. The properties of the resultant material are sensitive to processing conditions. In particular, the conductivity of the films depends strongly on the subsequent heat treatment. The requirement of vacuum annealing treatment to reduce resistivities by an order of magnitude has been established. It was determined that the out-diffusion of oxygen during the sample vacuum annealing was a determinant factor directly associated with the electrical activity of the dopant. Regardless of their nature and composition, the presence of neutral defects may play a decisive role that justifies the regress of the measured mobility especially at high indium content. Relatively more densely packed films are obtained when subjected to vacuum annealing regardless of the dopant level. Very transparent films can be obtained. The band gap shift remains below that theoretically predicted, probably due to the high concentration of neutral impurities. The effect of these impurities on band-gap narrowing should be considered with the electron-electron and electron-ion scattering.

\section{References}

[1] Jin, Z.-C., Hamberg, I. and Granqvist, C.G. (1988) Optical Properties of Sputter-Deposited ZnO:Al Thin Films. Journal of Applied Physics, 64, 5117. http://dx.doi.org/10.1063/1.342419

[2] Lee, J.-H., Lee, S.-Y. and Park, B.-O. (2006) Fabrication and Characteristics of Transparent Conducting $\mathrm{In}_{2} \mathrm{O}_{3}-\mathrm{ZnO}$ Thin Films by Ultrasonic Spray Pyrolysis. Materials Science and Engineering B, 127, 267-271. http://dx.doi.org/10.1016/j.mseb.2005.10.008 
[3] Addou, M., Moumin, A., El Idrissi, B., Regragui, M., Bougrine, A., Kachouane, A. and Monty, C. (1999) Structural, Optical and Electrical Properties of Undoped and Indium Doped Zinc Oxide Prepared by Spray Pyrolysis. Journal de Chimie Physique, 96, 232-244. http://dx.doi.org/10.1051/jcp:1999133

[4] Castañeda, L., Morales-Saavedra, O.G., Cheang-Wong, J.C., Acosta, D.R., Bañuelos, J.G., Maldonado, A. and Olvera, M.L. (2006) Influence of Indium Concentration and Substrate Temperature on the Physical Characteristics of Chemically Sprayed ZnO:In Thin Films Deposited from Zinc Pentanedionate and Indium Sulfate. Journal of Physics: Condensed Matter, 18, 5105-5120. http://dx.doi.org/10.1088/0953-8984/18/22/010

[5] Castañeda, L., Maldonado, A., Escobedo-Morales, A., Avendaño-Alejo, M., Gómez, H. Vega-Pérez, J. and Olvera, M.L. (2011) Indium Doped Zinc Oxide Thin Films Deposited by Ultrasonic Spray Pyrolysis Technique: Effect of the Substrate Temperature on the Physical Properties. Materials Science in Semiconductor Processing, 14, 114-119. http://dx.doi.org/10.1016/j.mssp.2011.01.013

[6] Biswal, R., Castañeda, L., Moctezuma, R., Vega-Pérez, J., Olvera, M.L. and Maldonado, A. (2012) Formation of Indium-Doped Zinc Oxide Thin Films Using Ultrasonic Spray Pyrolysis; the Importance of the Water Content in the Aerosol Solution and the Substrate Temperature for Enhancing Electrical Transport. Materials, 5, 432-442. http://dx.doi.org/10.3390/ma5030432

[7] Major, S., Banerjee, A. and Chopra, K.L. (1984) Annealing Studies of Undoped and Indium-Doped Zinc Oxide. Thin Solid Films, 122, 31-43. http://dx.doi.org/10.1016/0040-6090(84)90376-6

[8] Major, S., Banerjee, A. and Chopra, K.L. (1983) Highly Transparent and Conducting Indium-Doped Zinc Oxide Films by Spray Pyrolysis. Thin Solid Films, 108, 333-340. http://dx.doi.org/10.1016/0040-6090(83)90082-2

[9] Reddy, P.S., Chetty, G.R., Uthanna, S., Naidu, S. and Reddy, P.J. (1991) Optical Properties of Spray Deposited ZnO Films. Solid State Communications, 77, 899-901. http://dx.doi.org/10.1016/0038-1098(91)90342-S

[10] Ortiz, A. and Garcia, M. (1992) Photoluminescent Properties of Indium-Doped Zinc Oxide Films Prepared by Spray Pyrolysis. Thin Solid Films, 207, 175-180. http://dx.doi.org/10.1016/0040-6090(92)90119-V

[11] Lo, C.Y., Hsu, C.L., Yu, Q.X., Lee, H.Y. and Lee, C.T. (2002) Investigation of Transparent and Conductive Undoped $\mathrm{Zn}_{2} \mathrm{In}_{2} \mathrm{O}_{5-\mathrm{x}}$ Films Deposited on $n$-Type GaN Layers. Journal of Applied Physics, 92, 274. http://dx.doi.org/10.1063/1.1481207

[12] Lim, J.H., Hwang, D.K., Kim, H.S., Oh, J.Y., Yang, J.H., Navamathavan, R. and Park, S.J. (2004) Low-Resistivity and Transparent Indium-Oxide-Doped ZnO Ohmic Contact to p-Type GaN. Applied Physics Letters, 85, 6191. http://dx.doi.org/10.1063/1.1826231

[13] Nomura, K., Ohta, H., Ueda, K., Orita, M., Hirano, M. and Hosono, H. (2002) Novel Film Growth Technique of Single Crystalline $\mathrm{In}_{2} \mathrm{O}_{3}(\mathrm{ZnO})_{m}(m=$ integer) Homologous Compound. Thin Solid Films, 411, 147-151. http://dx.doi.org/10.1016/S0040-6090(02)00204-3

[14] Galca, A.C., Socol, G. and Cracium, V. (2012) Optical Properties of Amorphous-Like Indium Zinc Oxide and Indium Gallium Zinc Oxide Thin Films. Thin Solid Films, 520, 4722-4725. http://dx.doi.org/10.1016/j.tsf.2011.10.194

[15] Kim, P.Y., Lee, J.Y., Lee, H.Y., Lee, S.J. and Cho, N.I. (2008) Structure and Properties of IZO Transparent Conducting Thin Films Deposited by PLD Method. Journal of Korean Physical Society, 53, 207-211.

[16] Jeon, J.W., Jeon, D.W., Sahoo, T., Kim, M., Baek, J.H., Hoffman, J.L., Kim, N.S. and Lee, I.H. (2011) Effect of Annealing Temperature on Optical Band-Gap of Amorphous Indium Zinc Oxide Film. Journal of Alloys and Compounds, 509, 10062-10065. http://dx.doi.org/10.1016/j.jallcom.2011.08.033

[17] Ohashi, N., Ogino, T., Sakaguchi, I., Hishita, S., Komatsu, M., Takenaka, T. and Haneda, H. (2002) Fabrication of Epitaxial $\mathrm{In}_{2} \mathrm{O}_{3}(\mathrm{ZnO})_{5}$ Thin Films by RF Sputtering and Their Characterization by X-Ray and Electron Diffraction Techniques. Journal of Crystal Growth, 237-239, 558-563. http://dx.doi.org/10.1016/S0022-0248(01)01980-7

[18] Moriga, T., Okamoto, T., Hiruta, K., Fujiwara, A., Nakaayashi, I. and Tominaga, K. (2000) Structures and Physical Properties of Films Deposited by Simultaneous DC Sputtering of $\mathrm{ZnO}$ and $\mathrm{In}_{2} \mathrm{O}_{3}$ or ITO Targets. Journal of Solid State Chemistry, 155, 312-319. http://dx.doi.org/10.1006/jssc.2000.8919

[19] Phillips, J.M., Cava, R.J., Thomas, G.A., Carter, S.A., Kwo, J., Siegrist, T., Krajewski, J.J., Marshall, J.H., Peck, W.F. and Rapkine, D.H. (1995) Zinc-Indium-Oxide: A High Conductivity Transparent Conducting Oxide. Applied Physics Letters, 67, 2246-2248. http://dx.doi.org/10.1063/1.115118

[20] Harding, G.L., Window, B. and Horrigan, E.C. (1991) Aluminum- and Indium-Doped Zinc Oxide Films Prepared by DC Magnetron Reactive Sputtering. Solar Energy Materials, 22, 69-91. http://dx.doi.org/10.1016/0165-1633(91)90007-8

[21] Luna-Arredondo, E.J., Maldonado, A., Asomoza, R., Acosta, D.R., Meléndez-Lira, M.A. and de la L. Olvera, M. (2005) Indium-Doped ZnO Thin Films Deposited by the Sol-Gel Technique. Thin Solid Films, 490, 132.

[22] Kim, M.S., Yim, K.G., Kim, S., Nam, G., Lee, D.Y., Kim, J.S., Kim, J.S. and Leem, J.Y. (2012) Growth and Characterization of Indium-Doped Zinc Oxide Thin Films Prepared by Sol-Gel Method. Acta Physica Polonica A, 121, 217- 
220.

[23] Bahadur, H., Srivastava, A.K., Sharma, R.K. and Chandra, S. (2007) Morphologies of Sol-Gel Derived Thin Films of ZnO Using Different Precursor Materials and Their Nanostructure. Nanoscale Research Letters, 2, 469-475. http://dx.doi.org/10.1007/s11671-007-9089-X

[24] Bel Hadj Tahar, R., Ban, T., Ohya, Y. and Takahashi, Y. (1997) Optical, Structural, and Electrical Properties of Indium Oxide Thin Films Prepared by the Sol-Gel Method. Journal of Applied Physics, 82, 865-870. http://dx.doi.org/10.1063/1.365786

[25] Major, S. and Chopra, K.L. (1988) Indium-Doped Zinc Oxide Films as Transparent Electrodes for Solar Cells. Solar Energy Materials, 17, 319-327. http://dx.doi.org/10.1016/0165-1633(88)90014-7

[26] Bel Hadj Tahar, R. (2005) Structural and Electrical Properties of Aluminum-Doped Zinc Oxide Films Prepared by Sol-Gel Process. Journal of the European Ceramic Society, 25, 3301-3306. http://dx.doi.org/10.1016/j.jeurceramsoc.2004.08.028

[27] Bel Hadj Tahar, R. and Bel Hadj Tahar, N. (2005) Crystallographic Orientation in Pure and Aluminum-Doped Zinc Oxide Thin Films Prepared by Sol-Gel Technique. Journal of the American Ceramic Society, 88, 1725-1728. http://dx.doi.org/10.1111/j.1551-2916.2005.00268.x

[28] Lide, D.R. (1991) Handbook of Chemistry and Physics. 71st Edition, CRC Press, Boca Raton.

[29] Bel Hadj Tahar, R. and Bel Hadj Tahar, N. (2005) Boron-Doped Zinc Oxide Thin Films Prepared by Sol-Gel Technique. Journal of Materials Science, 40, 5285-5289. http://dx.doi.org/10.1007/s10853-005-0522-1

[30] Goyal, D.J., Agashe, C., Takwale, M.G., Bhide, V.G., Mahamuni, S. and Kulkarni, S.K. (1993) Dopant Induced Modifications in the Physical Properties of Sprayed ZnO:In Films. Journal of Materials Research, 8, 1052-1056. http://dx.doi.org/10.1557/JMR.1993.1052

[31] Bel Hadj Tahar, R. and Bel Hadj Tahar, N. (2002) Mechanism of Carrier Transport in Aluminum-Doped Zinc Oxide. Journal of Applied Physics, 92, 4498-4501.

[32] Jin, Z.C., Hamberg, I. and Granqvist, C.G. (1987) Optical Properties of Transparent and Heat Reflecting ZnO:Al Films Made by Reactive Sputtering. Applied Physics Letters, 51, 149-151. http://dx.doi.org/10.1063/1.99008

[33] Frank, G. and Köstlin, H. (1982) Electrical Properties and Defect Model of Tin-Doped Indium Oxide Layers. Applied Physics A, 27, 197-206. http://dx.doi.org/10.1007/BF00619080

[34] Ku, D.Y., Kim, I.H., Lee, I., Lee, K.S., Lee, T.S., Jeong, J.H., Cheong, B., Baik, Y.J. and Kim, W.M. (2006) Structural and Electrical Properties of Sputtered Indium-Zinc Oxide Thin Films. Thin Solid Films, 515, 1364-1369. http://dx.doi.org/10.1016/j.tsf.2006.03.040

[35] Qiu, S.N., Qiu, C.X. and Shih, I. (1987) Air Heat Treatment of In-Doped ZnO Thin Films. Solar Energy Materials, 15, 261-267. http://dx.doi.org/10.1016/0165-1633(87)90041-4

[36] Qiu, C.X. and Shih, I. (1986) Tin- and Indium-Doped Zinc Oxide Films Prepared by RF Magnetron Sputtering. Solar Energy Materials, 13, 75-84. http://dx.doi.org/10.1016/0165-1633(86)90036-5

[37] Castro, M.S. and Aldao, C.M. (1999) Effects of the Sintering Temperature on the Oxygen Adsorption in ZnO Ceramics. Journal of the European Ceramic Society, 19, 511-515. http://dx.doi.org/10.1016/S0955-2219(98)00210-6

[38] Srikant, V. and Clark, D.R. (1998) On the Optical Band Gap of Zinc Oxide. Journal of Applied Physics, 83, 5447. http://dx.doi.org/10.1063/1.367375

[39] Pearton, S.J., Norton, D.P., Ip, K., Heo, Y.W. and Steiner, T. (2005) Recent Progress in Processing and Properties of ZnO. Progress in Materials Science, 50, 293-340.

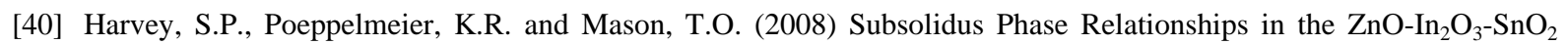
System. Journal of the American Ceramic Society, 91, 3683-3689. http://dx.doi.org/10.1111/j.1551-2916.2008.02686.x

[41] Mari, B., Cembrero, J., Mollar, M. and Tortosa, M. (2008) Optical Properties of Zinc Oxide-Based Ternary Compounds Synthesized by Electrodeposition. Physica Status Solidi (c), 5, 555-558. http://dx.doi.org/10.1002/pssc.200776840

[42] Sarkar, A., Ghosh, S., Chaudhuri, S. and Pal, A.K. (1991) Studies on Electron Transport Properties and the BursteinMoss Shift in Indium-Doped ZnO Films. Thin Solid Films, 204, 255-264. http://dx.doi.org/10.1016/0040-6090(91)90067-8

[43] Weijtens, C.H.L. and Van Loon, P.A.C. (1991) Influence of Annealing on the Optical Properties of Indium Tin Oxide. Thin Solid Films, 196, 1-10. http://dx.doi.org/10.1016/0040-6090(91)90169-X

[44] Roth, A.P., Webb, J.B. and Williams, D.F. (1982) Band-Gap Narrowing in Heavily Defect-Doped ZnO. Physical Review B, 25, 7836-7839. http://dx.doi.org/10.1103/PhysRevB.25.7836

[45] Caporaletti, O. (1982) Electrical and Optical Properties of Bias Sputtered ZnO Thin Films. Solar Energy Materials, 7, 65-73. http://dx.doi.org/10.1016/0165-1633(82)90097-1 
[46] Major, S., Banerjee, A. and Chopra, K.L. (1985) Optical and Electronic Properties of Zinc Oxide Films Prepared by Spray Pyrolysis. Thin Solid Films, 125, 179-185. http://dx.doi.org/10.1016/0040-6090(85)90411-0

[47] Major, S., Banerjee, A. and Chopra, K.L. (1986) Electrical and Optical Transport in Undoped and Indium-Doped Zinc Oxide Films. Journal of Materials Research, 1, 300-310. http://dx.doi.org/10.1557/JMR.1986.0300

[48] Burstein, E. (1954) Anomalous Optical Absorption Limit in InSb. Physical Review, 93, 632. http://dx.doi.org/10.1103/PhysRev.93.632

[49] Sernelius, B.E., Berggren, K.F., Jin, Z.C., Hamberg, I. and Granqvist, C.G. (1988) Band-Gap Tailoring of ZnO by Means of Heavy Al Doping. Physical Review B, 37, 10244-10248. http://dx.doi.org/10.1103/PhysRevB.37.10244

[50] Hamberg, I., Granqvist, C.G., Berggren, K.F., Sernelius, B.E. and Engström, L. (1984) Band-Gap Widening in Heavily Sn-Doped $\operatorname{In}_{2} \mathrm{O}_{3}$. Physical Review B, 30, 3240-3249. http://dx.doi.org/10.1103/PhysRevB.30.3240

[51] Wolff, P.A. (1962) Theory of the Band Structure of Very Degenerate Semiconductors. Physical Review, $126,405$. http://dx.doi.org/10.1103/PhysRev.126.405

[52] Dietz, R.E., Hopfield, J.J. and Thomas, D.G. (1961) Excitons and the Absorption Edge of ZnO. Journal of Applied Physics, 32, 2282. http://dx.doi.org/10.1063/1.1777060

[53] Shooji, S., Minami, T., Takata, S. and Nanto, H. (1984) Rep. IECE of Japan Tech. Group on Electron Parts and Materials, CMP 84-4, 55.

[54] Sernelius, B.E. (1987) Self-Energy Shifts in Heavily Doped, Polar Semiconductors. Physical Review B, 36, $4878-4887$. http://dx.doi.org/10.1103/PhysRevB.36.4878

[55] Hamberg, I. and Granqvist, C.G. (1986) Evaporated Sn-Doped $\operatorname{In}_{2} \mathrm{O}_{3}$ Films: Basic Optical Properties and Applications to Energy-Efficient Windows. Journal of Applied Physics, 60, R123-R159. http://dx.doi.org/10.1063/1.337534 
Scientific Research Publishing (SCIRP) is one of the largest Open Access journal publishers. It is currently publishing more than 200 open access, online, peer-reviewed journals covering a wide range of academic disciplines. SCIRP serves the worldwide academic communities and contributes to the progress and application of science with its publication.

Other selected journals from SCIRP are listed as below. Submit your manuscript to us via either submit@scirp.org or Online Submission Portal.
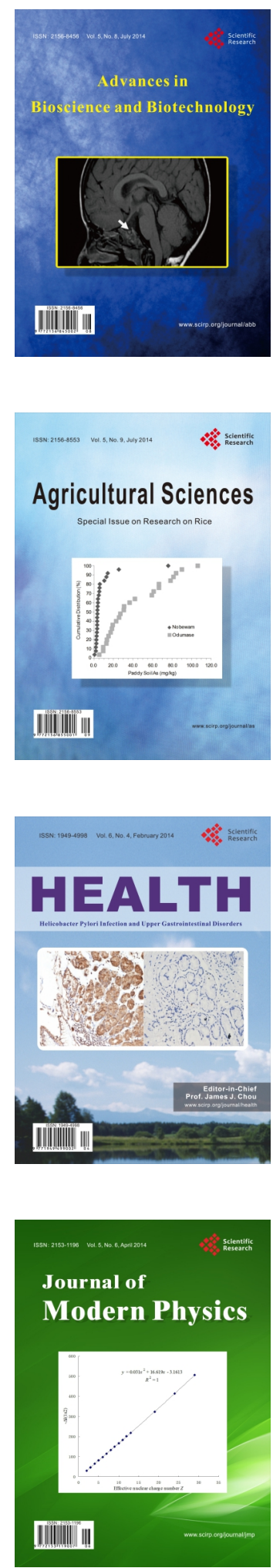
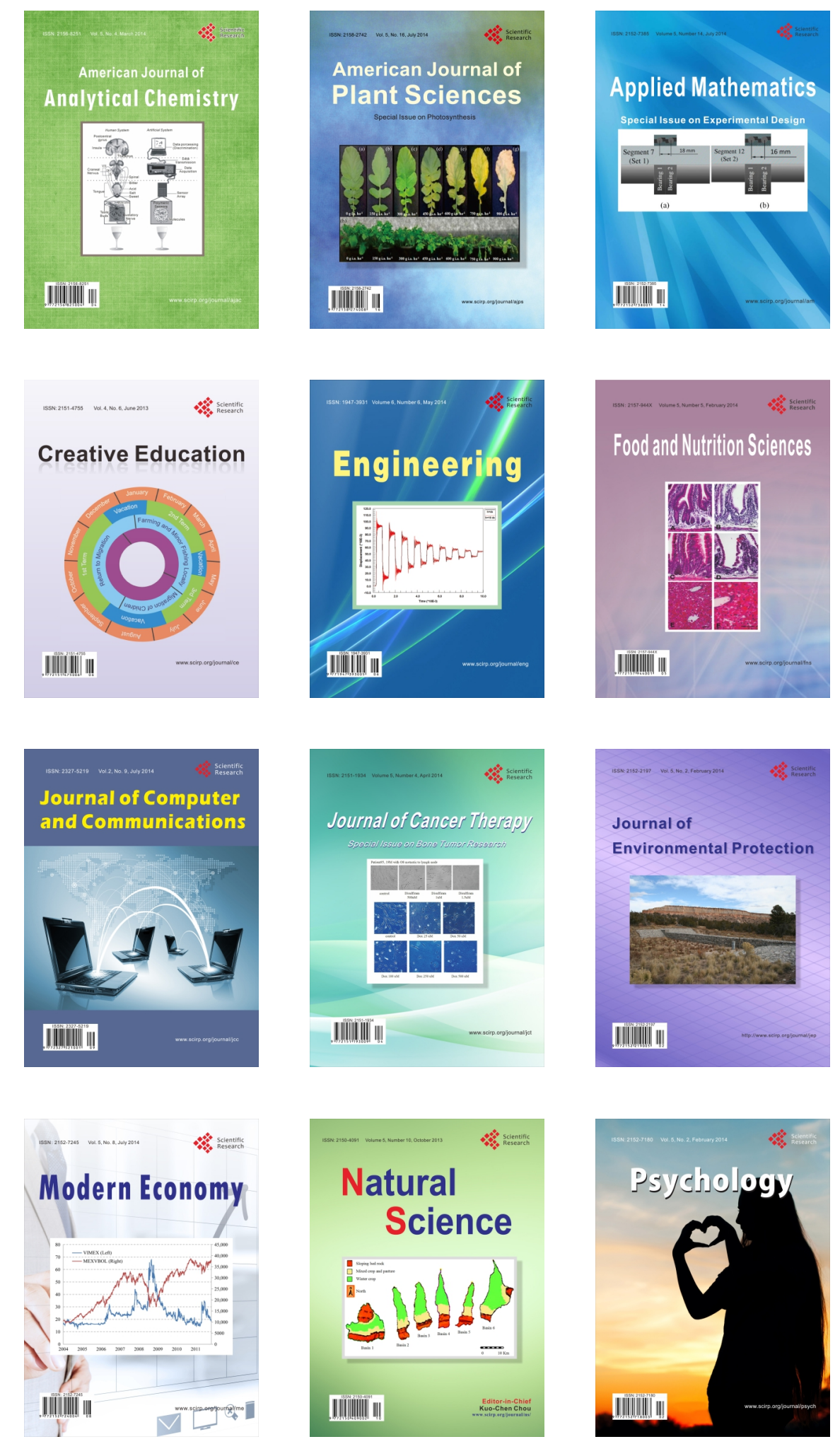